\title{
The Physical Properties of Inulin Solutions
}

\author{
BY C. F. PHELPS \\ Department of Biochemistry, University of Bristol
}

(Received 6 July 1964)

\begin{abstract}
1. Carefully recrystallized samples of inulin have been analysed chromatographically for low-molecular-weight contaminants. The analysis of the samples revealed amounts of low-molecular-weight polyfructosans amounting to 5-10\% of the inulin. 2. The possible polymorphism of inulin, its solubility behaviour and suggestions of association in solution are discussed. 3. Physical techniques suggest considerable polydispersity. Ultracentrifugation gives a weight-average molecular weight $\left(M_{w}\right) 7250$, whereas osmotic-pressure measurements suggest a numberaverage molecular weight $\left(M_{n}\right) 5600$. 4. A probable steric model is suggested of a helix repeating every four residues, of diameter $12 \AA$ and axial ratio 7·5-10. 5 . Fractionation of the inulin on columns of Sephadex G-25 show a pronounced polydispersity. 6. Some doubt is cast on the reliability of inulin as an indicator of physiological volumes of distribution in body fluids.
\end{abstract}

The extensive use of inulin solutions to indicate volumes of distribution in the extracellular fluid of tissues, and glomerular filtration rates in renal physiology, rests on the assumption that inulin is a homogeneous high-molecular-weight non-metabolized polysaccharide.

Reports of considerable polydispersity by Cotlove (1954a) and Bassir (1956) and the finding of $2-3 \%$ of glucose in inulin, which is discussed by Holzer, Wittmann-Zinke \& Zinke (1957), have raised doubts as to the metabolic inertness and homogeneity of the substance, and have also cast suspicion on the results obtained in physiological experiments with this polysaccharide. Work by Ogston \& Phelps (1960) on the dialysis of inulin into solutions of hyaluronic acid complex have confirmed the existence of the problem.

The present paper reports work on the characteristics and stability of the inulin molecule in solution, as determined by physical techniques, and attempts to assess its degree of polydispersity by fractionation on dextran-gel columns.

\section{MATERIALS AND METHODS}

Inulin. Two samples were used: $A$, bacteriological sugar reagent from Kerfoot Ltd., Vale of Bardsley, Lancs.; $B$, laboratory reagent from British Drug Houses Ltd., Poole, Dorset. All chemicals were analytical-reagent grade where available.

Determination of ash content. Ash was determined gravimetrically after combustion of weighed samples of inulin in porcelain crucibles.

Determination of fructose and low-molecular-weight contaminants. These were chromatographically determined by the descending method, with butan-1-ol-pyridine-water (6:4:3, by vol.) as solvent, on sheets of Whatman no. 2 paper $(57 \mathrm{~cm} . \times 46 \mathrm{~cm}$.). Chromatography for $72 \mathrm{hr}$. was required at room temperature for resolution of fructosans with degree of polymerization 12. Five successive spots, each of $10 \mu \mathrm{l}$., of a $1 \%$ solution were applied and development was performed with a freshly prepared spray containing $50 \mathrm{mg}$. of resorcinol, $125 \mathrm{mg}$. of thiourea, $50 \mathrm{ml}$. of conc. $\mathrm{HCl}$ and $50 \mathrm{ml}$. of acetic acid. The chromatogram was airdried and then heated at $60^{\circ}$ in an oven for $12 \mathrm{~min}$. The limit of sensitivity was about $1 \mu \mathrm{g}$. of fructose. The contaminants were estimated by the intensity and area of colour developed in the paper concerned, according to the method of Fisher, Parsons \& Morrison (1948).

Determination of water content. Drying overnight in an oven at $105^{\circ}$ removed much water. The remainder was removed by placing the oven-dried sample in a vacuum desiccator over $\mathrm{P}_{2} \mathrm{O}_{5}$.

Recrystallization. Two methods were used. In the first, quantities of inulin were dissolved in distilled water containing aq. $\mathrm{NH}_{3}$ (sp.gr. 0.88$)(0.1 \mathrm{ml} . / 100 \mathrm{ml}$. of solution). This solution was warmed to not more than $60^{\circ}$ and quickly filtered through fluted Whatman no. 42 papers into cooled flasks. The contents were cooled at $-15^{\circ}$ and then allowed to warm up to room temperature, when the inulin was obtained in an apparently crystalline form that was filtered off and dried in a vacuum desiccator. In the second method, quantities of inulin were dissolved as indicated above, and to the cool filtrate ethanol was added to make the resulting solution $30 \%(v / v)$ with respect to ethanol. The first slight precipitate was discarded and the ethanol concentration increased to $50 \%(\nabla / v)$, and this precipitate was collected and washed on filter paper with ethanol.

Determination of inulin. Inulin was determined quantitatively by the method of Kulka (1956).

Determination of solubility. A simple method that gave consistent results was to place an excess of inulin in a $10 \mathrm{ml}$. glass centrifuge tube that, together with its bucket, 
was immersed in a water bath. Distilled water was added to the tube and the contents were stirred. After $15 \mathrm{~min}$. the tube and bucket were removed and centrifuged for 2 min., and the supernatant was removed for analysis, at the same time the temperature of the solution being taken. The heat capacity of the bucket was sufficient in the short period of centrifugation to preserve the temperature of the centrifuge tube contents at within $3^{\circ}$ of the water-bath temperature. The possibility of slight supersaturation can therefore not be overlooked, but can be assumed to be small in relation to the small temperature difference observed. The solubility at $100^{\circ}$ for water-recrystallized inulin, and at $60^{\circ}$ for ethanol-recrystallized inulin, was determined by adding weighed amounts of the sample to $10 \mathrm{ml}$. of distilled water in a glass-stoppered tube until saturation became evident, when the solution was cooled and the volume in which the inulin was dissolved was measured.

Determination of osmotic pressure. Osmotic pressures were measured by a static method. Dialysis thimbles of collodion (type GC) were made by the method of Krogh (1922) and contained $10 \mathrm{ml}$. of air-free solute. They were attached to a rubber bung through which passed a capillary tube, and were suspended in $100 \mathrm{ml}$. of solvent. The capillary tube was moved downwards into the solute so as to give a pressure of about $25 \mathrm{~cm}$. of solute in Expts. 1 and 3, and $6 \mathrm{~cm}$. of solute in Expt. 2. Capillary corrections had been determined previously. Readings of the solute meniscus were taken with a cathetometer whose vertical traverse was calibrated to $0.01 \mathrm{~mm}$.

Determination of sedimentation coefficient. Sedimentation coefficients were calculated from measurements on a Svedberg oil-turbine analytical ultracentrifuge operated at $25-28^{\circ}$ at the Department of Biochemistry, University of Oxford, according to the method of Svedberg \& Pedersen (1940). Sedimentation coefficients corrected to water as solvent at $20^{\circ}$ were calculated by Professor A. G. Ogston by the method of Cecil \& Ogston (1948).

Determinations of viscosity. A standard Ostwald viscometer was used, immersed in a water bath whose temperature was controlled to $\pm 0 \cdot 01^{\circ}$. The flow time for water was $143.3 \mathrm{sec}$. for $1 \mathrm{ml}$. at $20^{\circ}$.

Gel filtration. Sephadex G-25 (fine and medium grades), a gift from Pharmacia, Sweden, was used. The powder was made up in $1 \%(w / v) ~ N a C l$ and sedimented under gravity, and the finest particles were removed by decantation before pouring into a column of internal diam. $2 \mathrm{~cm}$. to a height of $30 \mathrm{~cm}$. The void volume of Sephadex G-25 (medium grade) for cytochrome $c$ was found to be $27 \mathrm{ml}$. Fractions $(5 \mathrm{ml}$.) of effluent were collected on a fraction collector.

\section{RESULTS}

\section{Preliminary investigations and the choice of recrystallization method}

The preliminary analysis of inulin samples consisted in determinations of ash after combusion, and water content after drying in the oven and vacuum desiccation. Fructose and low-molecularweight contaminants were estimated chromatographically. The quantitative assessment of impurities by this method is very rough, but as its main object was to act as a standard of comparison between different preparations it was considered satisfactory.

Inulin is a fructosan (Haworth, Perceval \& Hirst, 1932), and, being a furanoside, is easily hydrolysed, even by dissolved carbon dioxide. For this reason, the solutions were made in slightly alkaline water, and two methods of recrystallization were employed. The first depended on the fact that many fructosans can be obtained in microscopically 'crystalline' form by cooling a solution to $-15^{\circ}$ and allowing it to warm up to room temperature. The second method depended on the ability of ethanol to precipitate inulin from aqueous solutions, and a method of fractional recrystallization was employed. The contents of ash, fructose and lowmolecular-weight contaminants in these recrystallized polysaccharides, as compared with the original material, are shown in Table 1. From this, the water-recrystallized sample possessed the least contaminants. A pilot experiment indicated that the temperature at which the original inulin was dissolved, and the time at that temperature, determined the amount of fructose liberated. When the inulin was dissolved in boiling slightly alkaline water, the proportion of fructosans with degree of polymerization 2-8 increased markedly, as compared with solutions at $60^{\circ}$. Inulin is only slightly

\section{Table 1. Contents of ash, fructose and low-molecular-weight polyfructosans in inulin samples}

Experimental details are given in the text. The values in the columns marked * refer to the intensity and area of colour developed on the chromatogram in the spots concerned compared with the total colour produced. The recrystallized samples had been extensively dried, and therefore had negligible water content. D.P. refers to the degree of polymerization of the fructosans.

Inulin

Sample $A$ (original)

Sample $B$ (original)

Sample $A$ (water-recrystallized)

Sample $B$ (water-recrystallized)

Sample $A$ (ethanol-recrystallized)

Sample $B$ (ethanol-recrystallized)

$\begin{array}{cc}\begin{array}{c}\text { Ash } \\ \text { g./100g. })\end{array} & \begin{array}{c}\text { Water } \\ \text { (g./100g.) }\end{array} \\ 0.05 & 9 \cdot 7 \\ 0.08 & 11 \cdot 1 \\ 0.006 & - \\ 0.006 & - \\ 0.005 & - \\ 0.006 & -\end{array}$

0.006

Fructose*
$10-15 \%$
$12-20 \%$
$0.5 \%$
$0.5 \%$
$2.5 \%$
$2.5 \%$

Fructosans (D.P. 2-8)*

$5-10 \%$
$8-15 \%$
$1-5 \%$
$1-5 \%$
$5-10 \%$
$5-10 \%$

Fructosans

(D.P. 10-14)*

$$
\begin{aligned}
& >10 \% \\
& >10 \% \\
& 5-10 \% \\
& 5-10 \% \\
& 5-10 \% \\
& 5-10 \%
\end{aligned}
$$


Table 2. Solubility of inulin in water

Experimental details are given in the text.

\begin{tabular}{|c|c|c|c|c|c|c|c|}
\hline & & & & ity (g.) & & & \\
\hline Temp........ & $0^{\circ}$ & $15^{\circ}$ & $30^{\circ}$ & $45^{\circ}$ & $60^{\circ}$ & $75^{\circ}$ & $100^{\circ}$ \\
\hline Sample $A$ (water-recrystallized) & 0.01 & & & 0.53 & 1.57 & & \\
\hline $\begin{array}{l}\text { Sample } A \text { (water-recrystallized) } \\
\text { Sample } B \text { (water-recrystallized }\end{array}$ & $\begin{array}{l}0.02 \\
0.01\end{array}$ & $\begin{array}{l}0.02 \\
0.04\end{array}$ & $0 \cdot 19$ & 0.46 & $1 \cdot 62$ & $\begin{array}{l}3.81 \\
3.91\end{array}$ & 33.2 \\
\hline Sample $A$ (ethanol-recrystallized) & 0.20 & $0 \cdot 32$ & 0.58 & $1 \cdot 12$ & $47 \cdot 0$ & - & - \\
\hline Sample $B$ (ethanol-recrystallized) & 0.20 & $0 \cdot 37$ & 0.55 & $1 \cdot 16$ & $49-0$ & - & - \\
\hline
\end{tabular}

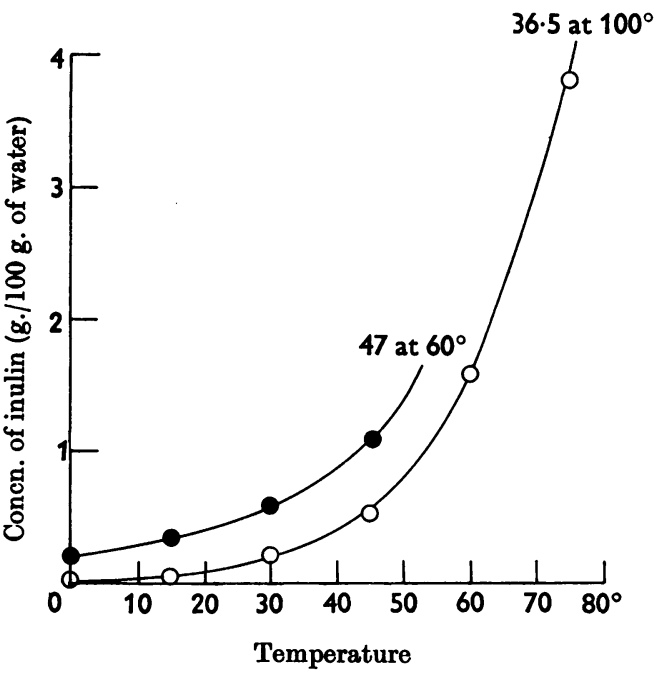

Fig. 1. Solubility of inulin in water at various temperatures. Experimental details are given in the text. $\bigcirc$, Sample $A$ (water-recrystallized); , sample $B$ (ethanol-recrystallized).

soluble in the cold, and rapid heating to $60^{\circ}$ gave the best compromise between considerable solubility and slight breakdown.

\section{Stability of inulin solutions}

It was noticed that inulin solutions, after standing for 3-5 days, threw down a precipitate. The solubility of inulin in water was therefore explored, with results in agreement with Yanofsky \& Kingsbury (1933). The results are shown in Table 2 and Fig. 1.

On cooling solutions of inulin from a high to a low temperature 'supersaturation' occurs, and the excess of inulin remains in a clear stable solution for about 3-5 days, after which inulin is visibly precipitated in variable amounts, though the amount left in solution is still in excess of the determined solubility even after 10 days. Even the ethanol-recrystallized inulin in saturated solution precipitates inulin in time, its solubility tending to decrease to that of the water-recrystallized sample. Osmotic-pressure measurements were undertaken to clarify the confusion in solubility. Three series of five osmometers were set up. In the first, the collodion bags were filled with a solution of water-recrystallized inulin saturated at $45^{\circ}$ and cooled to $20^{\circ}$. The second and third series of osmometers contained water-recrystallized and ethanol-recrystallized inulin respectively saturated at $20^{\circ}$. All measurements were taken at $20^{\circ}$, and after various times the solvent was analysed for material, reacting as fructose, that was found to dialyse across the semipermeable membrane. The inulin solution was also analysed for soluble inulin. The results are shown in Table 3. The falling osmotic pressure might be explained by gross leakage, but this was contraindicated by tests with serum albumin as solute, when stable osmotic pressures were obtained in $45 \mathrm{hr}$. at $20^{\circ}$ and no protein could be detected in the solvent. The results suggest that inulin may undergo polymerization at $20^{\circ}$ on standing. In addition, material reacting as fructose continues to dialyse through the membrane at a constant rate even after $136 \mathrm{hr}$. The most reproducible molecular weights were obtained from solutions of the waterrecrystallized inulin.

\section{Physicochemical investigations on solutions of inulin}

Sedimentation coefficient. There appears to have been no attempt in the past to determine the sedimentation coefficient of inulin solutions. The result of one series of experiments with inulin in phosphate buffer is shown in Table 4.

Intrinsic viscosity. The viscosity of inulin solutions is very similar to that of water. To determine the intrinsic viscosity $([\eta])$ with any degree of accuracy requires either an Ostwald viscometer of very long water-outflow time (approx. 1000 sec.) or very concentrated solutions. However, measurements were taken on the density and time 
Table 3. Osmotic pressure of inulin solutions

Solution I was saturated at $45^{\circ}$ and cooled to $20^{\circ}$; solution II was prepared at $20^{\circ}$, and both were samples of water-recrystallized material. Solution III was prepared at $20^{\circ}$, but from ethanol-recrystallized material. Measurements were taken at $20^{\circ}$. After $70 \mathrm{hr}$., the solutions I and III were seen to contain white precipitated material, which was also seen in solution II after $120 \mathrm{hr}$. Each osmometer contained $10 \mathrm{ml}$. of solution (solute) and $100 \mathrm{ml}$. of solvent. Experimental details are given in the text. Molecular weights were calculated from the osmotic pressure and the concentration of inulin at the time of measurement.

Solution I

Osmotic pressure $\left(\mathrm{cm} . \mathrm{H}_{2} \mathrm{O}\right)$

Time (hr.)......0

20

35

70

108

136

Inulin in solute (g./100 ml.)

\begin{tabular}{|c|c|c|c|c|c|}
\hline & 30.01 & $28 \cdot 22$ & 23.87 & 16.59 & 12.92 \\
\hline 0.568 & 0.557 & 0.530 & 0.461 & 0.318 & 0.262 \\
\hline- & 0.010 & 0.020 & 0.040 & 0.080 & 0.090 \\
\hline - & - & 0.0018 & 0.0057 & 0.0170 & 0.0216 \\
\hline- & 4250 & 4575 & 4705 & 4670 & 4940 \\
\hline - & $7 \cdot 36$ & $6 \cdot 83$ & 6.02 & $5 \cdot 56$ & $5 \cdot 10$ \\
\hline 0.150 & $0 \cdot 148$ & $0 \cdot 136$ & $0 \cdot 123$ & $0 \cdot 118$ & $0 \cdot 107$ \\
\hline - & 0.005 & 0.010 & 0.020 & 0.025 & 0.030 \\
\hline - & - & 0.0004 & 0.0007 & 0.0007 & 0.0013 \\
\hline- & 4900 & 4850 & 4980 & 5170 & 5110 \\
\hline 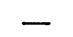 & $28 \cdot 90$ & $28 \cdot 20$ & $21 \cdot 60$ & $17 \cdot 16$ & $16 \cdot 07$ \\
\hline 0.537 & 0.515 & 0.492 & 0.393 & 0.325 & 0.302 \\
\hline & 0.002 & 0.004 & 0.007 & 0.010 & 0.011 \\
\hline & - & 0.010 & 0.074 & $0 \cdot 112$ & 0.125 \\
\hline & 4340 & 4250 & 4430 & 4615 & 4580 \\
\hline
\end{tabular}

Inulin unaccounted for (g. $/ 100 \mathrm{ml}$. of solute)

Molecular weight $\left(M_{n}\right)$

Solution II

Osmotic pressure $\left(\mathrm{cm} . \mathrm{H}_{2} \mathrm{O}\right)$

Inulin in solute (g./100 ml.)

Inulin in solvent $(\mathrm{g} . / 100 \mathrm{ml}$. of solute $/ 100 \mathrm{ml}$. of solvent)

Inulin unaccounted for $(\mathrm{g} . / 100 \mathrm{ml}$. of solute)

Molecular weight $\left(M_{n}\right)$

Solution III

Osmotic pressure $\left(\mathrm{cm} . \mathrm{H}_{2} \mathrm{O}\right)$

Inulin in solute (g./100 ml.)

Inulin in solvent (g./100 ml. of solute $/ 100 \mathrm{ml}$. of solvent)

Inulin unaccounted for (g./100 ml. of solute)

Molecular weight $\left(M_{n}\right)$

4340

\section{Table 4. Sedimentation coefficient of inulin solutions}

A $1 \%(w / v)$ solution of water-recrystallized inulin was made up in a buffer of composition: $\mathrm{NaCl}, 0 \cdot 20 \mathrm{M}$; $\mathrm{Na}_{2} \mathrm{HPO}_{4}, 7.7 \mathrm{mM} ; \mathrm{KH}_{2} \mathrm{PO}_{4}, 2.3 \mathrm{mM} ; \mathrm{pH} 7 \cdot 3$. Dilutions from this were made, as indicated. Experimental details

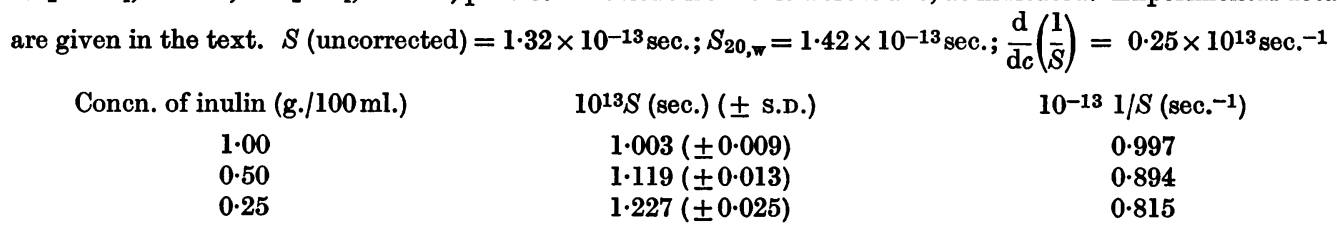

of outflow of a series of solutions, as shown in Table 5.

Partial specific volume. This quantity was measured by using a pycnometer of $5 \mathrm{ml}$. capacity. All measurements were performed at $20^{\circ}$, and the weights were accurate to $0 \cdot 1 \mathrm{mg}$. With waterrecrystallized from sample $A, \bar{v}$ was $0.601 \mathrm{~cm} .{ }^{3} / \mathrm{g}$.

Molecular weight. The molecular weight was determined by two methods:

(a) Osmotic pressure. Five osmometers were set up with inulin solutions from water-recrystallized material from sample $A$. The practice described above was followed and the results for the numberaverage molecular weight $\left(M_{n}\right)$ are shown in Table 6 .

(b) Light-scattering. Although the molecular weight of inulin is well below the limit normally accepted for light-scattering determinations, it was thought that any evidence obtainable by this method would serve to indicate a value for the weight-average molecular weight. Water-crystallized inulin from sample $A$ submitted to $\mathrm{Dr} \mathrm{P}$. Johnson at the Department of Colloid Science, University of Cambridge, gave a value of 7250 for the weight-average molecular weight $\left(M_{*}\right)$.

\section{Fractionation of inulin solutions}

Sufficient evidence had been collected to suggest that inulin solutions were extremely polydisperse. It was thought that columns of dextran gel (Sephadex G-25, fine grade) would provide a method of separating and measuring the molecular-weight distributions. To collect sufficient concentration of inulin in the eluate for both analysis and for 


\section{Table 5. Intrinsic viscosity of inulin solutions}

From a $1 \%(\mathrm{w} / \mathrm{v})$ solution of water-recrystallized inulin, dilutions were made as indicated. The temperature was $20.0 \pm 0.01^{\circ}$. The outflow time of the Ostwald viscometer ( $1 \mathrm{ml}$. of fluid) was 143.3 sec. Experimental details are given in the text.

$\begin{array}{cccccc}\text { Concn. of insulin }(\mathrm{g} . / 100 \mathrm{ml} .) & t_{\text {inulin }}(\mathrm{sec} .) & t_{\text {rel. }} & \eta_{\text {rel. }} & \eta_{\text {sp. }}\left(\eta_{\text {rel. }}-1\right) & \eta_{\text {sp. }} / c(\mathrm{~cm} .3 / \mathrm{g} .) \\ 0.1 & 144 \cdot 3 & 1.0070 & 1.0004 & 0.0073 & 0.073 \\ 0.3 & 146.2 & 1.0202 & 1.0016 & 0.0219 & 0.073 \\ 0.6 & 149 \cdot 4 & 1.0426 & 1.0034 & 0.0461 & 0.077 \\ 1.0 & 153 \cdot 7 & 1.0726 & 1.0055 & 0.0785 & 0.079\end{array}$

Whence $[\eta]\left(\lim _{c \rightarrow 0} \eta_{\text {sp. }} / c\right)=0.071 \mathrm{~cm} .3 / \mathrm{g}$.

Table 6. Osmotic pressure and molecular weight of inulin

The temperature was $20^{\circ}$, and equilibration was for $36 \mathrm{hr}$. The osmometers contained $10 \mathrm{ml}$. of solution in $100 \mathrm{ml}$. of solvent. Experimental details are given in the text.

$\begin{array}{cccr}\begin{array}{c}\text { Initial concn. of inulin } \\ (\mathrm{g} . / 100 \mathrm{ml} .)\end{array} & \begin{array}{c}\text { Final concn. of inulin } \\ (\mathrm{g} . / 100 \mathrm{ml})\end{array} & \begin{array}{c}\text { Osmotic pressure } \\ \left(\mathrm{cm} . \mathrm{H}_{2} \mathrm{O}\right)\end{array} & \frac{\pi}{c} \\ 0 \cdot 30 & 0 \cdot 29 & 16 \cdot 58 & 57 \cdot 2 \\ 0 \cdot 20 & 0 \cdot 20 & 11 \cdot 05 & 55 \cdot 3 \\ 0 \cdot 10 & 0 \cdot 10 & 5 \cdot 03 & 50 \cdot 3 \\ & \lim _{c \rightarrow 0} \frac{\pi}{c}=45 \cdot 0 ; M_{n}=R T / \frac{\pi}{c}=5640 . & \end{array}$

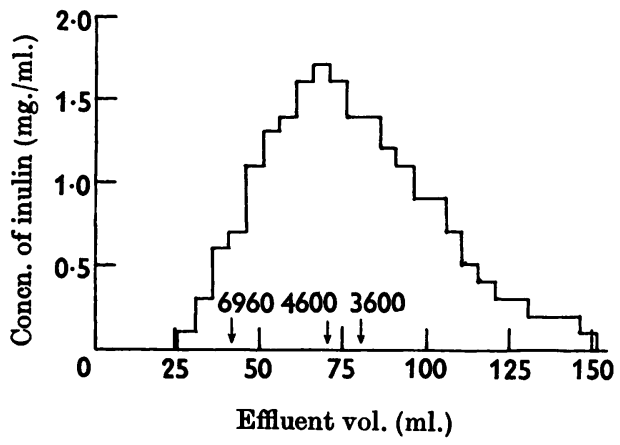

Fig. 2. Fractionation of inulin on Sephadex G-25 on a column $(2 \mathrm{~cm}$. internal diam. $\times 30 \mathrm{~cm}$. long). Experimental details are given in the text. The numbers above the abscissa of the graph represent $M_{n}$ values obtained from osmotic pressures by the method described in the text, and relate to the material collected at the indicated effluent volume.

molecular-weight determinations it was decided to use a moderately concentrated solution $(1 \%, \mathrm{w} / \mathrm{v})$. The column was run in a constant-temperature room at $40^{\circ}$. At this temperature a $1 \%$ solution of inulin is slightly supersaturated, but no precipitation occurred in the stock solution kept in the room during the 16-18hr. required for complete elution of the column. The results of such an analysis are shown in Fig. 2.

\section{DISCUSSION}

The object of the present work was to investigate the suitability of inulin to be a reliable indicator of extracellular-volume distributions in physiological experiments with tissues. The comparative rarity of metabolically-inert high-molecular-weight watersoluble substances would recommend inulin as the choice for such experiments, its size being such that it can pass through the capillaries but be excluded from the cells of the tissue. Before this claim can be met with any confidence, the basic facts about inulin should be reviewed.

Inulin is a polysaccharide that occurs in two main sources, chicory and dahlia tubers, from which it may be prepared commercially as a white hygroscopic powder. In the plant it serves the purpose of a storage polysaccharide, and Schlubach \& Elsner (1929) clearly stated the results of fractionation are greatly influenced by the stage of polymerization of the raw material, and that this varies with the plant species and the time of year. In spring the plant contains soluble lower fructosans and in autumn insoluble higher fructosans. The displacement of high-molecular-weight sugars from the tubers in spring was observed by Daniel (1924) and Thaysen, Bakes \& Green (1929).

The preliminary investigations undertaken in the present work reveal a high content of fructose and a very polydisperse distribution of fructosan 
components in the starting material. Recrystallization from water is shown to effect some purification. Further, the instability of solutions of inulin towards acid, even dissolved carbon dioxide, has been mentioned, and care must be taken in making up solutions to minimize this.

Cotlove $(1954 a, b)$ found that inulin was composed of two fractions, one of which, containing polyfructoside components of variable size, reducing oligosaccharides and free fructose, could be destroyed by recrystallizing the sample from hot dilute alkali. The fraction not destroyed by the alkali is chromatographically very similar to the water-recrystallized inulin sample described in the present work. The work of Bassir (1956) further indicates the heterogeneity of inulin.

The solubility curves of inulin pose some problems. The great increase in solubility between $60^{\circ}$ and $100^{\circ}$ must indicate a large change in structure of the molecule. The solubility does not obey the phase rule, and solutions saturated at a high temperature and cooled remain clear for some days. This metastable phenomenon is further complicated by the tendency for ethanol-recrystallized inulin to come out of saturated solution. The stability of these solutions is a subject of some importance. Equilibration with the extracellular compartment of intravascularly perfused inulin solutions may take 60-70hr. (White \& Rolf, 1956, 1957), and if there is a tendency for the polysaccharide to precipitate in this time then accumulation by the reticulo-endothelial system and deposition in renal parenchyma (Gayer, 1957) may be explained.

The tendency for the osmotic pressure to fall with time, suggesting polymerization of the inulin to larger units, and the concomitant steady release of material reacting as fructose, is a serious objection to the use of inulin in any equilibrium system, though the phenomenon is minimal in the sample of water-recrystallized inulin.

Two explanations of the instability of inulin solutions seem possible. In the first, the technique of dissolving may be assumed to cause some hydrolysis, and the polydisperse material may then recombine in solutions after long periods. A second possibility is that there may be a genuine polymorphism, as suggested by MacDonald (1946), with the water-recrystallized material representing one form whereas the ethanol-recrystallized and 'supersaturated' samples might represent an unstable second modification.

It seemed of some importance to attempt a characterization of the particle size, weight and axial asymmetry. The assembled findings from the present work, together with other supporting data from various sources, are shown in Table 7. The value of $D$ computed from the work of Bunim, Smith \& Smith (1937) pertains to a sample of

Table 7. Summary of physical data on inulin

Sedimentation coefficient $\left(S_{20, \mathrm{w}}\right)=1.42 \times 10^{-13} \mathrm{sec}$.

$\frac{\mathrm{d}}{\mathrm{d} c}\left(\frac{1}{\mathrm{~s}}\right)$

Intrinsic viscosity $([\mu])$

Partial specific volume $(\bar{v})$

Diffusion coefficient $(D)$

Molecular weight $\left(M_{20}\right)$

$\left(M_{n}\right)$

$$
\begin{aligned}
& =0.25 \times 10^{13} \mathrm{sec}^{-1} \\
& =0.071 \mathrm{~cm} .{ }^{3} / \mathrm{g} . \\
& =0.601 \mathrm{~cm} .3 / \mathrm{g} . \\
& =1.33 \times 10^{-6} \mathrm{~cm} .2 / \mathrm{sec} .{ }^{*} \\
& =7250 \\
& =5640 \dagger
\end{aligned}
$$

* Calculated from the data of Bunim et al. (1937).

$\dagger$ In agreement with the values obtained by Haworth et al. (1932) and Westfall \& Landis (1936).

carefully crystallized dahlia inulin and is used in these calculations as a supplementary parameter to confirm the general accuracy of the values for frictional ratio. It is possible then to calculate the dimensions and weight of the solute particle (Ogston, 1953).

The frictional ratio $f / f_{0}$ as determined from $S, D$ and $\bar{v}$ was $1 \cdot 38$, that from $S, \bar{v}$ and $M\left(M_{w} 7000\right)$ was $1 \cdot 37$, and that from $D, \vec{v}$ and $M\left(M_{\omega} 7000\right)$ was $1 \cdot 35$.

The molecular weight $M_{w}$ as determined from $S$, $\bar{v}$ and $D$ was 6500 .

If it is assumed that the value for the frictional ratio is due solely to asymmetry, then the axial ratio $(J)$ of the inulin particle is 7 . If, however, the same value is all due to solvation, then:

$$
\frac{\text { Solvated radius }(r)}{\text { Unsolvated radius }\left(r_{0}\right)}=1.38 \text { or }\left(\frac{r}{r_{0}}\right)^{8}=2 \cdot 6
$$

Further attempts to characterize the axial ratio by determining the values of functions of $J$ as recommended by Ogston (1953) are of doubtful significance in this case.

However, two steric models may be proposed:

(i) A flat ribbon of fructose units staggered in zigzag pattern. If the number of fructose units is taken as 30-40 and the length per fructose unit as $3.5 \AA$ (width $12 \AA$, thickness $3 \AA$ ), then the axial ratio $(J)$ would be in the range $9-12$.

(ii) A helix repeating every four residues. This would have a length of $12 \AA /$ four residues and a diameter of $12 \AA$, giving an axial ratio in the range 7·5-10. This latter postulated structure fits the facts more closely.

Finally, some doubt should be raised about the reliability of inulin as an extracellular-volume indicator in physiology. The present work suggests an unpredictable lability of the molecule that could cause uncertain errors in experiments of long duration. Its low diffusion coefficient at $20^{\circ}$ $\left(1.3 \times 10^{-6} \mathrm{~cm} .2 / \mathrm{sec}\right.$.) inevitably leads to longer periods before equilibration is reached in the 
extracellular-volume compartment, and an en- Holzer, K., Wittmann-Zinke, H. \& Zinke, A. (1957). M. hancement of the errors cited above.

I thank Professor A. G. Ogston, F.R.S., and Dr V. Coxon for valuable help in compiling this paper.

\section{REFERENCES}

Bassir, O. (1956). J. Physiol. 131, 586.

Bunim, J. J., Smith, W. W. \& Smith, H. W. (1937). J. biol. Chem. 118, 667.

Cecil, R. \& Ogston, A. G. (1948). Biochem. J. 43, 592.

Cotlove, E. (1954a). Fed. Proc. 13, 30.

Cotlove, E. (1954b). Amer. J. Physiol. 176, 396.

Daniel, L. (1924). C. R. Acad. Sci., Paris, 178, 1205.

Fisher, R. B., Parsons, D. S. \& Morrison, G. A. (1948). Nature, Lond., 161, 764.

Gayer, J. (1957). Klin. Wschr. 35, 568.

Haworth, W., Perceval, E. L. \& Hirst, E. G. V. (1932). J.chem. Soc. p. 2384.

Chem. 88, 11.

Krogh, A. (1922). The Anatomy and Physiology of Capillaries, p. 210. Yale.

Kulka, R. G. (1956). Biochem. J. 63, 542.

McDonald, E. J. (1946). Advanc. Carbohyd. Chem. 2, 253.

Ogston, A. G. (1953). Trans. Faraday Soc. 49, 1481.

Ogston, A. G. \& Phelps, C. F. (1960). Biochem. J. 78, 827.

Schlubach, H. H. \& Elsner, H. (1929). Ber. dtsch. chem. Ges. 62B, 1493.

Svedberg, T. \& Pedersen, K. O. (1940). The Ultracentrifuge. Oxford: The Clarendon Press.

Thaysen, A. C., Bakes, W. E. \& Green, B. M. (1929). Biochem.J. 23, 444.

Westfall, B. B. \& Landis, E. M. (1936). J. biol. Chem. 116, 727.

White, H. L. \& Rolf, D. (1956). Amer. J. Physiol. 185, 152.

White, H. L. \& Rolf, D. (1957). Amer. J. Physiol. 188, 151.

Yanofsky, E. \& Kingsbury, R. M. (1933). J. Amer. chem. Soc. 55, 3658. 